\title{
XELOX (capecitabine plus oxaliplatin) as first-line treatment for elderly patients over 70 years of age with advanced colorectal
}

\section{cancer}

\section{J Feliu*, , A Salud ${ }^{2}$, P Escudero ${ }^{3}$, L Lopez-Gómez ${ }^{4}$, M Bolaños ${ }^{5}$, A Galán ${ }^{6}$, J-M Vicent ${ }^{7}$, A Yubero ${ }^{8}$, F Losa9, J De Castro', MÁ de Mon ${ }^{10}$, E Casado' and M González-Barón' on behalf of the Oncopaz Cooperative Group and Associated Hospitals}

\begin{abstract}
'Service of Medical Oncology, H La Paz, Universidad Autónoma de Madrid, Paseo de la Castellana 26I, Madrid 28046, Spain; ${ }^{2}$ Service of Medical Oncology, H Arnau Vilanova, Avda. Alcalde Roure 80, Lérida 25006, Spain; ${ }^{3}$ Service of Medical Oncology, H Lozano Blesa, C/San Juan Bosco 15 , Zaragoza 50009, Spain; ${ }^{4}$ Service of Medical Oncology, H Virgen de la Salud, Avda. Barber 35, Toledo 45004, Spain; ${ }^{5}$ Service of Medical Oncology, H San Pedro de Alcántara Avda. Millán Astray s/n 10003 , Cáceres, Spain; ' Service of Medical Oncology, H Sagunto, Avda. Ramón y Cajal s/n46520, Valencia, Spain; ${ }^{7}$ Service of Medical Oncology, H General Universitario, Avda. Tres Cruces s/n460 I4, Valencia, Spain; ${ }^{8}$ Service of Medical Oncology, H Obispo Polanco, Avda. Ruiz Jarabo s/n44002, Teruel, Spain; ' 5 envice of Medical Oncology, H de la Creu Roja, Avda. Josep Molins 29-4 I, Hospitalet de Llobregat, 08906 Barcelona, Spain; ${ }^{10}$ Service of Medical Oncology, H Príncipe de Asturias, Ctra. Alcalá-Meco s/n Alcalá de Henares, 28880 Madrid, Spain
\end{abstract}

\begin{abstract}
The purpose of this phase II trial was to determine the efficacy and safety of the XELOX (capecitabine/oxaliplatin) regimen as firstline therapy in the elderly patients with metastatic colorectal cancer (MCRC). A total of 50 patients with MCRC aged $\geqslant 70$ years received oxaliplatin $130 \mathrm{mg} \mathrm{m}^{-2}$ on day | followed by oral capecitabine $1000 \mathrm{mg} \mathrm{m}^{-2}$ twice daily on days | - |4 every 3 weeks. Patients with creatinine clearance $30-50 \mathrm{ml} \mathrm{min}^{-1}$ received a reduced dose of capecitabine $\left(750 \mathrm{mg} \mathrm{m}^{-2}\right.$ twice daily). By intentto-treat analysis, the overall response rate was 36\% (95\% Cl, 28-49\%), with three (6\%) complete and I 5 (30\%) partial responses. In total, 18 patients $(36 \%)$ had stable disease and $14(28 \%)$ progressed. The median times to disease progression and overall survival were 5.8 months ( $95 \% \mathrm{Cl}, 3.9-7.8$ months) and 13.2 months $(95 \% \mathrm{Cl}, 7.6-16.9$ months), respectively. Capecitabine was well tolerated: grade $3 / 4$ adverse events were observed in 14 (28\%) patients: II (22\%) diarrhoea, eight (I6\%) asthenia, seven (I4\%) nausea/vomiting, three (6\%) neutropenia, three (6\%) thrombocytopenia, and two (4\%) hand-foot syndrome. There was one treatment-related death from diarrhoea and sepsis. In conclusion, XELOX is well tolerated in elderly patients, with respectable efficacy and a meaningful clinical benefit response. Given its ease of administration compared with combinations of oxaliplatin with 5-FU/LV, it represents a good therapeutic option in the elderly.

British Journal of Cancer (2006) 94, 969-975. doi: I 0.1038/sj.bjc.6603047 www.bjcancer.com

Published online 2I March 2006

(c) 2006 Cancer Research UK
\end{abstract}

Keywords: capecitabine; oxaliplatin; XELOX; metastatic colorectal cancer; elderly

Colorectal cancer (CRC) is the second most common cause of death from cancer in industrialised countries (Jemal et al, 2003) and its incidence increases with age (Gatta et al, 1998). Because of a progressively ageing population, it can be expected that the number of elderly with CRC will increase significantly in coming decades. However, chemotherapy is used less frequently in the elderly than in other age groups, in both the adjuvant (Potosky et al, 2002) and metastatic (Simmonds and Best, 1999; Sundarajan et al, 1999) settings. Factors that influence the resistance to use chemotherapy in the elderly include: a general lack of studies in this age group; the fear that the progressive reduction of functional reserve that occurs in various organs with ageing might increase the susceptibility of the elderly to adverse effects that can reduce

*Correspondence: Dr J Feliu; E-mail: jfeliu.hulp@salud.madrid.org Received 28 November 2005; revised 13 February 2006; accepted I5 February 2006; published online 21 March 2006 quality of life, particularly diarrhoea, mucositis, and myelosuppression (Balducci and Extermann, 2000) and comorbidity, which makes it difficult or impossible to use chemotherapy (De Marco et al, 2000).

Oxaliplatin and irinotecan are now established as first-line agents in the treatment of metastatic CRC (MCRC). The addition of oxaliplatin to 5-FU/leucovorin (LV) in first-line therapy has allowed an increase in response rates and time to disease progression (TTP) as compared to 5 -FU/LV alone (de Gramont et al, 2000; Douillard et al, 2000; Giacchetti et al, 2000; Saltz et al, 2000; Grothey et al, 2002). In addition, it has been found recently that the combination of oxaliplatin with infusional 5-FU/LV significantly increases response rate, TTP, and overall survival as compared to the combination of irinotecan with bolus 5-FU/LV (Goldberg et al, 2004). These regimens have the inconvenience of being based on the requirement for continuous infusion, which necessitates permanent venous access and the need to carry infusion apparatus/fluids. This increases the risk of 
catheter-related complications, such as infections (Clark and Raffin, 1990) or thromboembolism (Prandoni and Bernardi, 1990; Verso and Agnelli, 2003).

Oral chemotherapy avoids the costs and inconveniences associated with continuous infusions and is preferred to i.v. therapy given equal efficacy (Liu et al, 1997; Borner et al, 2002b). Capecitabine (Xeloda ${ }^{\mathbb{R}}$; Hoffmann-La Roche Inc., Nutley, NJ, USA) is an orally administered fluoropyrimidine designed to deliver 5-FU to tumour tissue (Miwa et al, 1998; Schüller et al, 2000). Large-scale, phase III trials have shown that capecitabine single-agent therapy is at least as effective and well tolerated as 5-FU/LV as first-line treatment for MCRC (Hoff et al, 2001; Van Cutsem et al, 2001) or as adjuvant therapy for stage III colon cancer (Scheithauer et al, 2003; Twelves et al, 2005). Furthermore, these trials showed that capecitabine had similar, favourable efficacy and safety in patients $<65$ or $\geqslant 65$ years. Various phase II/ III studies have shown similar efficacy and safety for combination of oxaliplatin with either oral capecitabine or infusional 5-FU/LV (Borner et al, 2002a; Zeuli et al, 2003; Cassidy et al, 2004; Shields et al, 2004, Arkenau et al, 2005; Ducreux et al 2005; Sastre et al, 2005), although experience with these regimens in the elderly is very limited in these studies, and usually excluded those $>75$ years. In fact, the vast majority of trials of any chemotherapeutic agents in MCRC have not included trials of patients $>70$ years.

Given the characteristics of this combination with respect to efficacy, safety, and ease of administration, the use of capecitabine/ oxaliplatin would be very attractive to use in the general population and particularly in the elderly in whom chemotherapy is usually restricted. Thus, the aim of our study was to analyse the efficacy and safety of the combination of capecitabine and oxaliplatin (XELOX) in patients $\geqslant 70$ years of age with advanced CRC.

\section{PATIENTS AND METHODS}

\section{Patient population}

Patients were required to be ambulatory and have an Eastern Cooperative Oncology Group (ECOG) performance status $\leqslant 2$, with a life expectancy of at least 3 months. All patients had measurable disease defined by the presence of at least one unidimensionally measurable lesion (RECIST criteria) (Therasse et $a l, 2000)$ by computed tomography scan. Pleural effusion, ascites, osteoblastic lesions, or previously irradiated lesions were not accepted as measurable disease.

Patients who had received prior adjuvant 5-FU-based chemotherapy were eligible if they had been disease free for at least 6 months after the completion of therapy. Patients who had received radiotherapy were eligible if there was at least one measurable lesion outside the radiation field. Other inclusion criteria were adequate haematological function (granulocyte count $\geqslant 2 \times 10^{9} 1^{-1}$ and platelets $>100 \times 10^{9} 1^{-1}$ ); adequate hepatic function (serum bilirubin $<1.25 \times$ the upper normal limit (UNL), glutamic oxaloacetic transaminase (SGOT), and glutamic pyruvic transaminases (SGPT) values $<2.5 \times \mathrm{UNL}$ in the absence of hepatic metastases or $<5 \times$ UNL in the presence of metastasis); alkaline phosphatase $<2.5 \times$ UNL in the absence of hepatic metastases or $<5 \times$ UNL or $10 \times$ UNL in the presence of hepatic or bone metastases and adequate renal function (creatinine clearance $\geqslant 30 \mathrm{ml} \mathrm{min}^{-1}$ ). All patients provided written informed consent according to local ethical committee directives.

Patients with operable metastatic disease were excluded from the study. Other exclusion criteria were as follows: clinically significant cardiac disease or myocardial infarction within the last 12 months; lack of physical integrity of the upper gastrointestinal tract or malabsorption syndrome; peripheral neuropathy of National Cancer Institute (NCI) grade 2 or greater; prior therapy with capecitabine, oxaliplatin, or irinotecan; known brain or meningeal metastases; and history of other malignancy, except basal cell carcinoma or adequately treated in situ cervical carcinoma.

Local research ethics committees approved the trial protocol and all patients provided written informed consent.

\section{Treatment plan}

The study regimen consisted of oxaliplatin $130 \mathrm{mg} \mathrm{m}^{-2}$ as 120 -min i.v. infusion on day 1 and oral capecitabine $1000 \mathrm{mg} \mathrm{m}^{-2}$ twice daily ( $2000 \mathrm{mg} \mathrm{m}^{-2}$ total daily dose) on days $1-14$ every 3 weeks. In patients with a creatinine clearance of $30-50 \mathrm{ml} \mathrm{min}^{-1}$, the dosage of capecitabine was reduced to $750 \mathrm{mg} \mathrm{m}^{-2}$ twice daily ( $1500 \mathrm{mg} \mathrm{m}^{-2}$ total daily dose). The dose of capecitabine was rounded to the next closest dose that could be administered using a combination of 500- and 150-mg tablets. The two daily doses of capecitabine were administered $12 \pm 2 \mathrm{~h}$ apart, $30 \mathrm{~min}$ after meals (breakfast and evening meal), with approximately $200 \mathrm{ml}$ of water.

The Cockcroft-Gault formula (Cockcroft and Gault, 1976) was used to calculate the creatinine clearance between cycles. If clearance was $<30 \mathrm{ml} \mathrm{min}^{-1}$, treatment was interrupted. Cycles were repeated every 3 weeks for a minimum of three per patient, unless disease progressed. Patients with a partial response or stable disease continued chemotherapy until progression or the development of unacceptable adverse events. Patients could also continue capecitabine monotherapy after discontinuation of oxaliplatin because of toxicity.

Patients were evaluated for adverse events before each cycle and graded according to NCI Common Toxicity Criteria (version 2.0). For hand-foot syndrome, the previously published grading system was used (Blum et al, 1999). Dose reduction/interruption for capecitabine according to adverse event grade was performed as previously described (Blum et al, 1999). The oxaliplatin dose was reduced by $25 \%$ in the event of grade 3 or 4 thrombocytopenia, grade 4 neutropenia, or any other severe ( $\geqslant$ grade 3 ) organ toxicity, and for paresthesiae with pain or functional impairment $>7$ days, or paresthesiae with pain persistent between cycles. For paresthesiae with functional impairment persistent between cycles, oxaliplatin was discontinued. Treatment could be delayed for up to 2 weeks if symptomatic toxicity persisted, the absolute neutrophil count was lower than $1 \times 10^{9} 1^{-1}$, or the platelet count was lower than $75 \times 10^{9} 1^{-1}$. Subcutaneous administration of granulocyte colony-stimulating factor $5 \mu \mathrm{g} \mathrm{kg} \mathrm{day}{ }^{-1}$ on 5 consecutive days was recommended in the former group of patients. Any patient who required more than 2 weeks for recovery from adverse reactions was excluded from the study.

\section{Pretreatment and follow-up evaluation}

A diagnostic work-up was performed within 3 weeks prior to the start of treatment, consisting of a complete clinical history, physical examination, blood analysis (haematology and complete biochemistry), and imaging studies as needed (chest X-ray, computed tomography of the chest, abdomen and pelvis, abdominal ultrasound, and bone scan). The Charlson comorbidity scale (Charlson et al, 1987), Katz Activity of Daily Living (ADL) index (Katz et al, 1963), and Lawton Instrumental Activity of Daily Living (IADL) index (Lawton, 1998) were used in patient assessment. Patients' ECOG performance status and weight were also recorded. An ECG was performed in all patients prior to receiving study treatment. Symptom assessment, physical examination, and blood biochemistry were repeated before each treatment cycle. Tumour measurements were taken every three cycles or sooner if clinically indicated.

Patients and/or caregivers were given a card indicating the number of pills that they were to take per day: they were asked to record the dose actually taken and give the card back to the doctor at the next visit. 


\section{Response criteria}

Patients were evaluated clinically at least every 3 weeks and radiographically every 9 weeks. The same evaluation modality was used throughout the study. The RECIST response guidelines were used (Therasse et al, 2000), defining all responses after at least 9 weeks of therapy as follows: complete response (CR), partial response $(\mathrm{PR})$, stable disease $(\mathrm{SD})$, or progressive disease $(\mathrm{PD})$. We defined disease control as the sum of patients achieving a CR, PR, or SD. Confirmation of all responses was required after 4 weeks. The TTP was estimated from the dates of the first course of treatment to the first documentation of disease progression. Survival was calculated by the same method from the date of the first cycle of treatment until the date of death or last known follow-up.

\section{Symptoms assessment}

An assessment of clinical benefit was determined from a composite of pain intensity, analgesic consumption, ECOG performance status, weight loss, and the presence of anorexia and asthenia. The same doctor for each patient assessed ECOG performance status and symptoms before each chemotherapy cycle. Patients entered a pain stabilisation run-in period to establish baseline measures. Pain was assessed with the Memorial Pain Assessment Card (MPAC) (Fishman et al, 1987). Asthenia and anorexia were assessed using a visual analogue scale (VAS) of $0-100$. In addition, patients' weight was measured at each visit. Patients were considered to be evaluable for palliative benefits when they initially had one of the following signs or symptoms: an ECOG performance status $\geqslant 1$; an MPAC score $\geqslant 20$; baseline analgesic consumption of $\geqslant 10$ morphine equivalents $\mathrm{mg} \mathrm{day}^{-1}$; score on the VAS for anorexia and/or asthenia of $\geqslant 20$; or weight loss $>10 \%$ during the previous 6 months.

Symptom improvement was defined as an improvement of at least one score from baseline in ECOG performance status; $5 \%$ weight gain from baseline (patients with oedema, ascites, or pleural effusion were excluded from this category); or an improvement of $\geqslant 50 \%$ from baseline in disease-related symptoms (pain, use of analgesics, anorexia, and asthenia) and analgesic consumption (measured weekly in morphine-equivalent milligrams). Each of these improvements had to be sustained for at least 4 weeks (Cocconi et al, 1998).

\section{Statistical methods}

The primary end point of the trial was to determine the activity of the XELOX regimen in the intent-to-treat population. Secondary objectives were the safety profile, clinical benefit, TTP, and overall survival. Dose intensity was calculated for each patient from the total dose of capecitabine and oxaliplatin administered during the entire course of treatment and expressed as the mean drug dose in $\mathrm{mg} \mathrm{m}^{-2}$ week $^{-1}$.

An optimal two-stage design as described by Simon (1989) was used. A true response probability of $40 \%$ or greater was considered to be of interest, while further testing of the regimen would not be pursued if the response probability was $20 \%$ or lower. In the first stage, a total of 13 patients were included and at least four responses (CR or PR) were required to continue to the second stage. In the second stage, 30 additional patients were included plus $10 \%$ to allow for losses. Univariate analysis was used to compare the rate of grade $3 / 4$ adverse events according to age $(70-79$ years $v s \geqslant 80$ years), gender, creatinine clearance $(<50 v s$ $\left.\geqslant 50 \mathrm{ml} \mathrm{min}^{-1}\right)$, Charlson comorbidity scale $(0 v s \geqslant 1)$, ECOG performance status $(0 v s \geqslant 1)$, and ADL and IADL (independent $v s$ dependent). Wilcoxon's signed-rank test (to compare quantitative variables) and Fisher's exact test (to compare percentages) were used. Overall survival and TTP were calculated using the KaplanMeier method.

\section{RESULTS}

\section{Patient characteristics}

From January 2003 to September 2003, 54 patients from 11 centres were included. Four patients were excluded from analysis because they did not meet all selection criteria. Their mean age was 76 (range, 70-82) years. The demographic and clinical characteristics of the patients are shown in Table 1, while Table 2 shows their functional assessments. One-third of patients were metastatic at the time of diagnosis, although only one-third had received prior adjuvant therapy. In five patients (10\%), the primary tumour was not resected. The median time from the primary diagnosis of CRC to inclusion was 14.6 months. Regarding symptoms, 38 patients had significant symptoms at baseline evaluation, which included asthenia $(56 \%)$, pain $(40 \%)$, and anorexia $(28 \%)$. In total, 28 patients $(56 \%)$ had comorbid conditions, mainly hypertension, arthritis, obstructive lung disease, peptic ulcer disease, diabetes, coronary insufficiency, and cardiovascular conditions. Comorbidity was present in 20 (40\% of) patients when using the Charlson scale (Charlson et al, 1987).

\section{Treatment duration}

A total of 286 cycles of treatment were administered, with a median of five per patient (range 1-8 cycles). Eight (16\%) patients received less than three cycles of XELOX, due to disease progression $(n=2,4 \%)$, because of adverse events $(n=3,6 \%)$, treatment-related death $(n=1,2 \%)$, lost to follow-up $(n=1,2 \%)$, and refusal to continue treatment $(n=1,2 \%)$. Nevertheless, all of

Table I Patient characteristics at study entry $(n=50)$

\begin{tabular}{|c|c|}
\hline Characteristic & Patients (\%) \\
\hline \multicolumn{2}{|l|}{ Age (years) } \\
\hline $70-75$ & 56 \\
\hline $76-79$ & 32 \\
\hline$\geqslant 80$ & 12 \\
\hline \multicolumn{2}{|l|}{ Gender } \\
\hline Male & 72 \\
\hline Female & 28 \\
\hline \multicolumn{2}{|l|}{ ECOG performance status } \\
\hline 0 & 52 \\
\hline I & 46 \\
\hline 2 & 2 \\
\hline \multicolumn{2}{|l|}{ Location of primary tumour } \\
\hline Colon & 68 \\
\hline Rectum & 28 \\
\hline Both & 4 \\
\hline \multicolumn{2}{|l|}{ No. of metastatic sites } \\
\hline । & 74 \\
\hline$\geqslant 2$ & 26 \\
\hline \multicolumn{2}{|l|}{ Differentiation } \\
\hline Well differentiated & 10 \\
\hline Moderately differentiated & 60 \\
\hline Poorly differentiated & 18 \\
\hline Undetermined/unknown & 12 \\
\hline \multicolumn{2}{|l|}{ Sites of metastasis } \\
\hline Liver & 64 \\
\hline Lung & 32 \\
\hline Lymph node & 14 \\
\hline Other & 24 \\
\hline
\end{tabular}

$\mathrm{ECOG}=$ Eastern Cooperative Oncology Group. 
Table 2 Functional assessments at entry $(n=50)$

\begin{tabular}{lc}
\hline Functional assessment & Patients (\%) \\
\hline Activity of daily living index & \\
No dependence & 58 \\
Light dependency & 24 \\
Moderate dependency & 14 \\
Serious dependency & 4 \\
& \\
Instrumental activity of daily living index & \\
Autonomous & 58 \\
Light dependency & 30 \\
Moderate dependency & 8 \\
Serious dependency & 4 \\
Charlson comorbidity scale & \\
0 & \\
I & 60 \\
2 & 26 \\
3 & 8 \\
\hline
\end{tabular}

the patients enrolled were considered evaluable for both efficacy and safety. A total of $23(46 \%)$ patients experienced treatment delays during the study for causes unrelated to the treatment $(n=10,20 \%)$, haematological adverse events $(n=5,10 \%)$, and nonhaematological adverse events $(n=8,16 \%)$. The median dose intensity of capecitabine was higher for patients with creatinine clearance $>50 \mathrm{ml} \mathrm{min}^{-1}\left(9.22 \mathrm{~g} \mathrm{~m}^{-2}\right.$ week $\left.^{-1}\right)$, and for the remaining 14 patients with creatinine clearance between 30 and $50 \mathrm{ml} \mathrm{min}^{-1}\left(7.68 \mathrm{~g} \mathrm{~m}^{-2}\right.$ week $\left.^{-1}\right)$. These doses correspond to 86 and $98 \%$ of the predicted dose intensity, respectively. The median dose intensity of oxaliplatin was $39.8 \mathrm{mg} \mathrm{m}^{-2}$ week $^{-1}$, which corresponded to $92 \%$ of the predicted dose intensity. During the course of their disease, 12 patients $(24 \%)$ needed a central venous access: two during the XELOX treatment, six during the secondline treatment, and the rest of the patients after completion of chemotherapy for symptomatic treatment purposes.

\section{Efficacy}

The assessment of response was performed on the ITT population of 50 eligible patients. Of these, three patients $(6 \%$ of the eligible population) had a CR and $15(30 \%)$ a PR. A total of 18 patients (36\%) maintained SD and $14(28 \%)$ had PD. The overall response rate was $36 \%$ (95\% confidence interval (CI), 23-49\%). There was no relationship between the rate of response and the location of metastases, ECOG performance status, ADL, IADL, or patients' age.

The median TTP was 5.8 months (95\% CI, 3.9-7.8 months; Figure 1), median overall survival was 13.2 months (95\% CI, 7.6-16.9 months; Figure 2), and the actuarial survival per year was $51 \%$ (95\% CI, 37-65\%). Second-line chemotherapy based on irinotecan was subsequently administered in 12 patients $(24 \%)$.

Of the 50 enrolled patients, 38 were evaluable for symptoms or ECOG score response. The remaining 12 patients were not evaluable for the following reasons: $\mathrm{ECOG}=0$, MPAC score $<20$, or VAS for anorexia and asthenia $<20$. Clinical benefit responses are summarised in Table 3 . Overall, 16 patients $(42 \%$; 95\% CI, 26.7-59.6\%) obtained an improvement in ECOG score and/or at least one symptom without worsening in other symptoms or ECOG score. The median duration of this improvement was 5.3 months (95\% CI, 2-12 months).

\section{Safety}

Treatment was generally well tolerated. In all, 32 patients (64\%) had an adverse event, usually grade $1 / 2$. The main adverse events

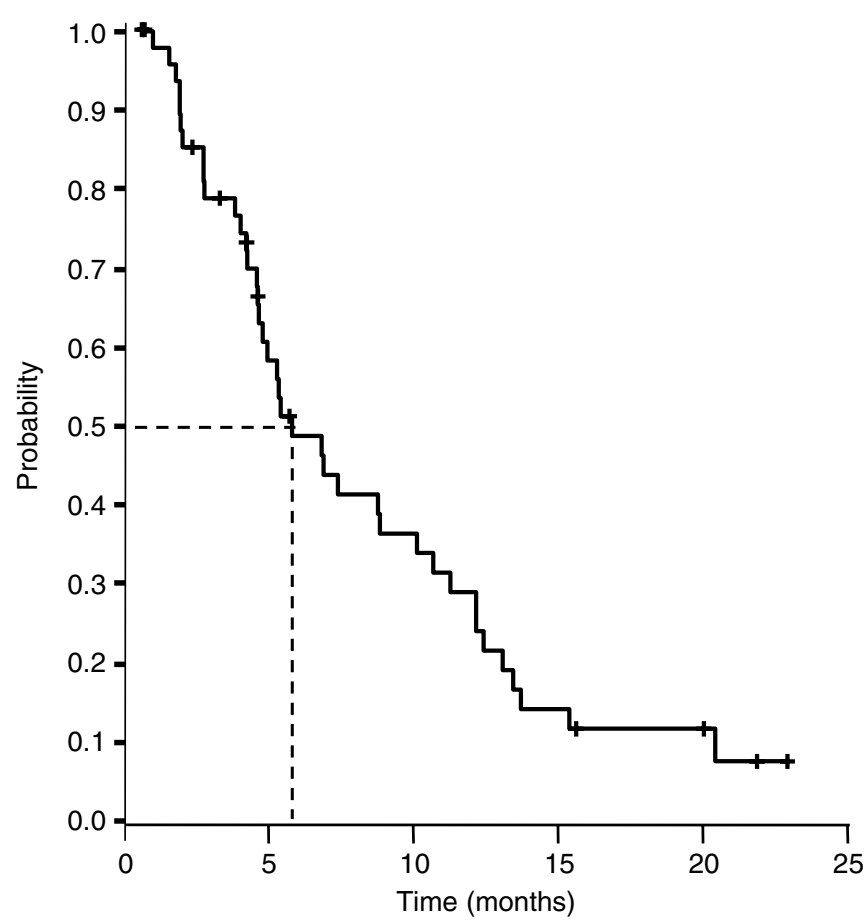

Figure I Time to disease progression $(n=50)$.

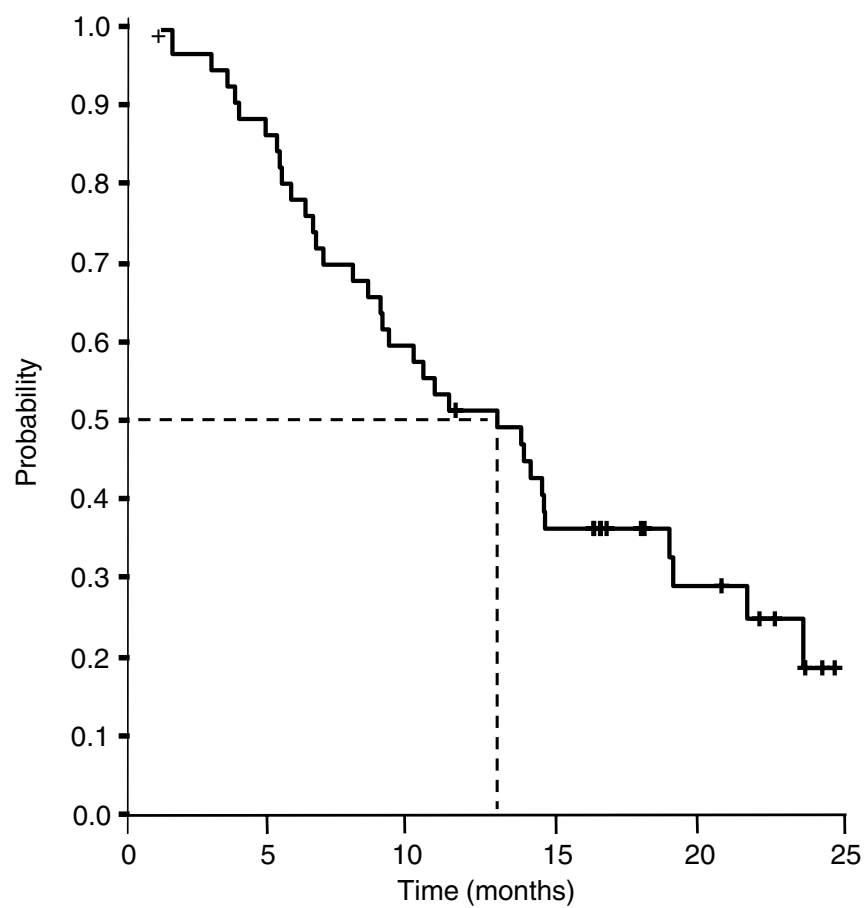

Figure 2 Overall survival $(n=50)$.

were gastrointestinal and haematological (Figure 3). A total of 14 patients (28\%) had grade 3/4 adverse events: 11 (22\%) diarrhoea, eight (16\%) asthenia, seven (14\%) nausea/vomiting, three $(6 \%)$ neutropenia, three $(6 \%)$ thrombocytopenia, two (4\%) hand-foot syndrome, and one each (2\%) with anaemia, mucositis, and sensory neuropathy, respectively. In a patient with a protocol violation, there was one treatment-related death due to diarrhoea 
Table 3 Effect of the treatment on performance status and symptom $(n=38)$

\begin{tabular}{lccc}
\hline & \multicolumn{3}{c}{ Patients (\%) } \\
\cline { 2 - 4 } Parameter & Improvement & Stabilisation & Worsening \\
\hline ECOG performance status & 20 & 60 & 20 \\
Pain & 23 & 63 & 14 \\
Anorexia & 26 & 54 & 20 \\
Asthenia & 37 & 37 & 26 \\
Weight loss & 26 & 60 & 14 \\
\hline
\end{tabular}

$\mathrm{ECOG}=$ Eastern Cooperative Oncology Group.

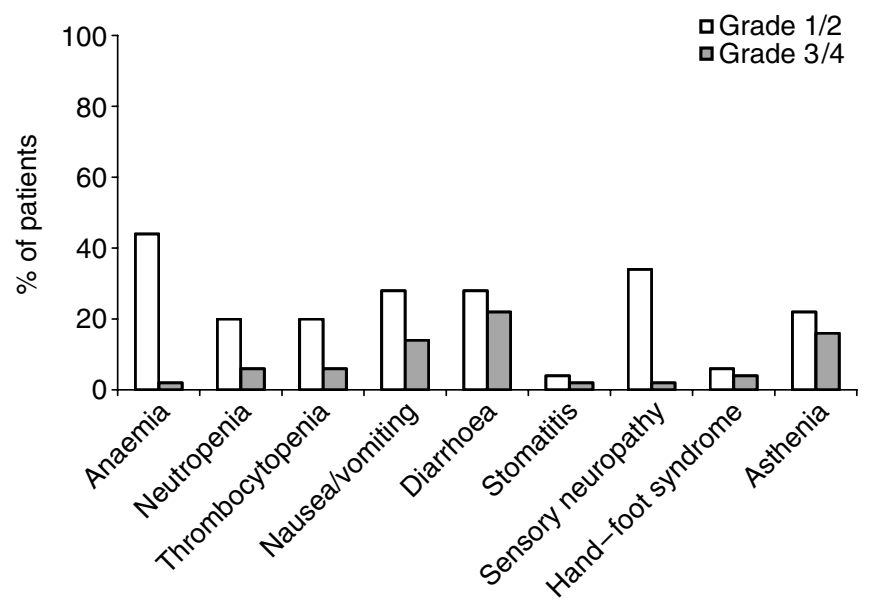

Figure 3 Adverse events by $\mathrm{NCl}-\mathrm{CTC}$ grade $(n=50)$.

and sepsis: the dose of capecitabine was not reduced to $75 \%$ due to creatinine clearance at $38 \mathrm{ml} \mathrm{min}^{-1}$.

An exploratory univariate analysis did not detect any relationships between the appearance of grade $3 / 4$ adverse events and age ( $70-79$ years $v s \geqslant 79$ years), gender, ADL, IADL, ECOG status, comorbidity, or renal function.

\section{DISCUSSION}

Currently, MCRC is an incurable disease. Thus, treatment must be directed at survival prolongation, symptom alleviation, and improving, or at least maintaining, the patient's quality of life. These objectives can be achieved using the administration of less toxic chemotherapy regimens that are easier to administer and do not require the patient to be hospitalised repeatedly. With the elderly, we have to be even more careful in the choice of treatment. It is necessary to consider other aspects that might influence tolerability, such as the pharmacokinetic and pharmacodynamic changes that appear with age (Lichtman, 2004) and comorbidity (Balducci and Extermann, 2000).

The aim of our study was to analyse the efficacy and safety of the XELOX regimen in elderly patients with MCRC. Our results, with a response rate of $36 \%$ and a median TTP of 5.8 months, are similar to those obtained by other authors with capecitabine/oxaliplatin (Borner et al, 2002a; Zeuli et al, 2003; Cassidy et al, 2004) in series that excluded patients aged $>75$ years. In contrast, median overall survival in our series was 13.2 months, which is somewhat less than the 17-20 months reached in these other studies (Borner et al, 2002a; Zeuli et al, 2003; Cassidy et al, 2004). However, median overall survival was similar to that obtained in studies performed exclusively in the elderly with MCRC who received combinations of 5-FU/LV plus oxaliplatin or irinotecan (Aparicio et al, 2003), or capecitabine plus oxaliplatin (Comella et al, 2005). It has been noted that the survival of patients with MCRC increases when they receive three active cytostatic agents (5-FU/LV, oxaliplatin, and irinotecan) during their disease course (Grothey et al, 2004; Tournigand et al, 2004). Thus, the shorter survival of the patients in our series might be attributable to the low proportion of elderly who received a second line of chemotherapy. For example, it is clear from this study that irinotecan was not a widely used second line. The frequent comorbidity that is often present might also contribute towards this. It would therefore appear necessary to increase the proportion of elderly to whom second-line treatment has been added after disease progression, especially if there is little comorbidity, or little or no ADL/IADL dependence. It is possible that the increasing availability of new targeted agents could increase the efficacy of treatment in elderly patients.

The XELOX regimen was generally well tolerated. In total, $28 \%$ of the patients experienced grade $3 / 4$ adverse events, which is comparable to the safety described with this capecitabine/ oxaliplatin in other series that included patients who were not elderly ((Borner et al, 2002a; Zeuli et al, 2003; Cassidy et al, 2004; Shields et al, 2004). The low rate of grade $3 / 4$ neurotoxicity in our patients might appear somewhat surprising at only $2 \%$, especially compared with the $17 \%$ reported by Cassidy et al (2004). However, given that the development of this toxicity depends on the total accumulated dose of oxaliplatin received during treatment, the low toxicity in our series can probably be attributed to the reduced number of treatment cycles received by our patients compared to the series of Cassidy et al (2004) (median 4.5 vs 8 cycles, respectively). On the other hand, the proportion of the elderly in our study that developed grade $3 / 4$ adverse events was similar to the $29 \%$ reported in another study performed exclusively in the elderly and which also used a capecitabine/oxaliplatin regimen, in which the dose of subsequent cycles was increased as a function of tolerability by the patient (Comella et al, 2005).

The good tolerability of the XELOX regimen in our series might, in part, be due to the dose of capecitabine used, which was adjusted for each cycle as a function of creatinine clearance (Gieschke et al, 2003; Feliu et al, 2005). We believe that this is important in the elderly. Moreover, the only toxic death in our study occurred in a patient where the dose was not appropriately adjusted because of his low creatinine clearance. The safety of XELOX was clearly better than when using combinations of 5-FU/ LV plus oxaliplatin in the elderly with MCRC: grade 3/4 adverse events occurred in $28 \%$ of patients in our series compared to $42-80 \%$ in series that received 5-FU/LV/oxaliplatin (Aparicio et al, 2003; Figer et al, 2004). Of particular note is the high rate of grade $3 / 4$ neutropenia that is seen with 5-FU/LV/oxaliplatin regimens, which varies in the elderly between 30 and 55\% according to the series considered (Giacchetti et al, 2000; Baretta et al, 2001; Aparicio et al, 2003; Mattioli et al, 2003; Figer et al, 2004), whereas this adverse event was detected in $<10 \%$ of patients with capecitabine/oxaliplatin (Borner et al, 2002a; Zeuli et al, 2003; Cassidy et al, 2004; Shields et al, 2004; Arkenau et al, 2005). Additionally in our study, we did not encounter any relationship between toxicity and certain factors that are generally presumed to be capable of predisposing to greater toxicity, such as female gender (Macdonald, 2002) comorbidity (Balducci and Extermann, 2000), performance status, etc. However, we acknowledge that the small number of patients means that our study might be insufficiently powered to detect these relationships.

In addition to the potential efficacy and safety advantages of replacing 5-FU with capecitabine, it is important to consider the ease of oral administration, which avoids the possible complications and inconveniences associated with the use of infusion 
apparatus or hospital admissions (Clark and Raffin, 1990; Prandoni and Bernardi, 1990; Verso and Agnelli, 2003). Also, the number of hospital visits can be reduced considerably to once every 3 weeks with XELOX, when the patient is routinely reviewed, oxaliplatin administered, and capecitabine dispensed. This might prove especially interesting in elderly patients, who usually require the assistance of a family member or helper to get to hospital. It is still important for patients to receive good quality educational materials and to have regular phone contact with their nurse/ physician. Patients with dependency for the daily activities of life may still require a caregiver who takes full responsibility of administering treatment and the early detection of adverse events. Furthermore, the addition of targeted therapy with bevacizumab can be conveniently integrated into the 3-weekly XELOX regimen with little impact on regimen convenience.

\section{REFERENCES}

Aparicio T, Desrame J, Lecomte T, Mitry E, Belloc J, Eitenney I, Montembault S, Vayre L, Locher C, Ezenfis J, Artru P, Mabro M, Dominguez S (2003) Oxaliplatin- or irinotecan-based chemotherapy for metastatic colorectal cancer in the elderly. Br J Cancer 89: 1439-1444

Arkenau H, Schmoll H, Kublicka S, Kretzschmar A, Freier W, Seufferlein T, Graeven U, Grothey A, Hinke A, Porschen R (2005) Infusional 5 -fluorouracil/folinic acid plus oxaliplatin (FUFOX) vs capecitabine plus oxaliplatin (CAPOX) as first line treatment of metastatic colorectal cancer (MCRC): results of the safety and efficacy analaysis. Proc Am Soc Clin Oncol 23: 247 (abstr. 3507)

Balducci L, Extermann M (2000) Management of cancer in the older person: a practical approach. Oncologist 5: 224-237

Baretta M, Bounadon M, Rupolo M, Frustaci S, Bearz A, Sorio R, Freschi A, Scalone S, Michieli M, Spina M, Tirelli U, Colussi AM, Cartei G (2001) Comparison between elderly and non-elderly patients (pts) of efficacy and tolerability of FOLFOX2 schedule in advanced colorectal cancer (col). Proc Am Soc Clin Oncol 20: 111 (abstr. 2195)

Blum JL, Jones SE, Buzdar AU, Lorusso PM, Kuter I, Vogel C, Osterwalder B, Burger HU, Brown CS, Griffin T (1999) Multicenter phase II study of capecitabine in paclitaxel-refractory metastatic breast cancer. J Clin Oncol 17: $485-493$

Borner MM, Dietrich D, Stupp R, Morant R, Honegger H, Wernli M, Herrmann R, Pestalozzi BC, Saletti P, Hanselmann S, Muller S, Brauchli P, Castiglione-Gertsch M, Goldhirsch A, Roth AD (2002a) Phase II study of capecitabine and oxaliplatin in first- and second-line treatment of advanced or metastatic colorectal cancer. J Clin Oncol 20: $1759-1766$

Borner MM, Schöffski P, de Wit R, Caponigro F, Comella G, Sulkes A, Greim G, Peters GJ, van der Born K, Wanders J, de Boer RF, Martin C, Fumoleau P (2002b) Patient preference and pharmacokinetics of oral modulated UFT $v s$ intravenous fluorouracil and leucovorin: a randomised crossover trial in advanced colorectal cancer. Eur J Cancer 38: $349-358$

Cassidy J, Tabernero J, Twelves C, Brunet R, Butts C, Conroy T, Debraud F, Figer A, Grossmann J, Sawada N, Schoffski P, Sobrero A, Van Cutsem E, Díaz-Rubio E (2004) XELOX (capecitabine plus oxaliplatin): active firstline therapy for patients with metastatic colorectal cancer. J Clin Oncol 22: $2084-2091$

Charlson ME, Pompei P, Ales KL, MacKenzie CR (1987) A new method of classifying prognostic comorbidity in longitudinal studies: development and validation. J Chronic Dis 40: $373-383$

Clark DR, Raffin TA (1990) Infectious complications of indwelling longterm central venous catheters. Chest 97: 966-972

Cocconi G, Cunningham D, Van Cutsem E, Francois E, Gustavsson B, van Hazel G, Kerr D, Possinger K, Hietschold SM (1998) Open, randomized multicenter trial of raltitrexed $v s$ fluorouracil plus high-dose leucovorin in patients with advanced colorectal cancer. J Clin Oncol 16: 2943-2952

Cockcroft DW, Gault MH (1976) Prediction of creatinine clearance from serum creatinine. Nephron 16: $31-41$

Comella P, Natale D, Farris A, Gambardella A, Maiorino L, Massidda B, Casaretti R, Tafuto S, Lorusso V, Leo S, Cannone M (2005) Capecitabine plus oxaliplatin for the first-line treatment of elderly patients with metastatic colorectal carcinoma. Cancer 104: 282 - 289
In summary, the results of our study show that the XELOX regimen represents a good therapeutic option in the fit elderly and in the patient partially dependent and with little severe comorbidity. In addition, it appears safer than that previously reported in studies with 5-FU/LV plus oxaliplatin, especially in the elderly. While we do not have available the results of phase III studies in the elderly comparing the efficacy and tolerability of the XELOX regimen $v s 5-\mathrm{FU} / \mathrm{LV}$ plus oxaliplatin, its convenience and ease of administration lead us to conclude that XELOX might be a good combination.

\section{ACKNOWLEDGEMENTS}

This study was supported by Roche, Spain. de Gramont A, Figer A, Seymour M, Homerin M, Hnissi A, Cassidy J, Boni C, Cortés-Funes H, Cervantes A, Freyer G, Papamichael D, Le Bail N, Louvet C, Hendler D, Braud F, Wilson C, Morvan F, Bonetti A (2000) Leucovorin and fluorouracil with or without oxaliplatin as first-line treatment in advanced colorectal cancer. J Clin Oncol 18: 2938-2947

De Marco MF, Heijnen ML, van der Heijnen LH, Coebergh JW (2000) Comorbidity and colorectal cancer according to subsite stage: a population-based study. Eur J Cancer 36: 95-99

Douillard JY, Cunningham D, Roth AD, Navarro M, James RD, Karasek P, Jandik P, Iveson T, Carmichael J, Alakl M, Gruia G, Awad L, Rougier P (2000) Irinotecan combined with fluorouracil compared with fluorouracil alone as first-line treatment for metastatic colorectal cancer: a multicentre randomised trial. Lancet 355: $1041-1047$

Ducreux M, Adenis A, Bennouna J, Conroy T, Faroux R, Hebbar M, Lledo G, Paillot B, Ychou M, Douillard J (2005) Phase II, randomized, openlabel study of capecitabine (X) plus oxaliplatin (XELOX) vs infusional 5FU/LV plus oxaliplatin (FOLFOX-6) first-line treatment in patients (pts) with metastatic colorectal cancer (MCRC): findings from an interim safety analysis. Proc Am Soc Clin Oncol 23: 270 (abstr. 3596)

Feliu J, Escudero P, Llosa F, Bolaños M, Vicent JM, Yubero A, Sanz-Lacalle JJ, López R, López Gómez L, Casado E, Gómez-Reina MJ, GonzálezBarón M (2005) Capecitabine is effective and well tolerated as first-line treatment for elderly patients over 70 years of age with advanced colorectal cancer. J Clin Oncol 23: 3104-3111

Figer A, Perez N, Carola E, Andre T, Chirivella I, Lledo G, Flesch M, Rivera F, Colin P, De Gramont A (2004) 5-Fluorouracil, folinic acid and oxaliplatin (FOLFOX) in very old patients with metastatic colorectal cancer. Proc Am Soc Clin Oncol 22: 263 (abstr. 3571)

Fishman B, Pasternak S, Wallenstein SL, Houde RW, Holland JC, Foley KM (1987) The memorial pain assessment card: a valid instrument for the evaluation of cancer pain. Cancer 60: $1151-1158$

Gatta G, Faivre J, Capocaccia R, Ponze de Leon M (1998) Survival of colorectal cancer patients in Europe during the period 1978-1989. EUROCARE Working Group. Eur J Cancer 34: 2176-2183

Giacchetti S, Perpoint B, Zidani R, Le Bail N, Faggiuolo R, Focan C, Chollet P, Llory JF, Letourneau Y, Coudert B, Bertheaut-Cvitovich F, LarregainFournier D, Le Rol A, Walter S, Adam R, Misset JL, Levy F (2000) Phase III multicenter randomized trial of oxaliplatin added to chronomodulated fluorouracil-leucovorin as first-line treatment of metastatic colorectal cancer. J Clin Oncol 18: 136-147

Gieschke R, Burger HU, Reigner B, Blesch KS, Steimer JL (2003) Population pharmacokinetics and concentration-effect relationships of capecitabine metabolites in colorectal cancer patients. Br J Clin Pharmacol 55: $252-263$

Goldberg RM, Sargent DJ, Morton RF, Fuchs CS, Ramanathan RK, Williamson SK, Findlay BP, Pilot HC, Alberts SR (2004) A randomized controlled trial of fluorouracil plus leucovorin, irinotecan, and oxaliplatin combinations in patients with previously untreated metastatic colorectal cancer. J Clin Oncol 22: 23-30

Grothey A, Deschler B, Kroening H, Ridwelski K, Reichardt P, Kretzschmar A, Clemens M, Hirschmann W, Lorenz M, Asperger W, Buechele T, Schmoll HJ (2002) Phase III study of bolus 5-fluorouracil (5-FU)/folinic acid (FA) (Mayo) vs weekly high-dose $24 \mathrm{~h} 5$-FU infusion/FA+oxaliplatin 
(OXA) (FUFOX) in advanced colorectal cancer (ACRC). Proc Am Soc Clin Oncol 21: 129 (abstr. 512)

Grothey A, Sargent D, Goldberg RM, Schmoll HJ (2004) Survival of patients with advanced colorectal cancer improves with the availability of fluorouracil-leucovorin, irinotecan, and oxaliplatin in the course of treatment. J Clin Oncol 22: 1209-1214

Hoff PM, Ansari R, Batist G, Cox J, Kocha W, Kuperminc M, Maroun J, Walde D, Weaver C, Harrison E, Burger HU, Osterwalder B, Wong AO, Wong R (2001) Comparison of oral capecitabine $v s$ intravenous fluorouracil plus leucovorin as first-line treatment in 605 patients with metastatic colorectal cancer: results of a randomized phase III study. J Clin Oncol 19: 2282-2292

Jemal A, Murray T, Samuels A, Chafoor A, Ward E, Thun MJ (2003) Cancer statistics, 2003. CA Cancer J Clin 53: 5-26

Katz S, Ford AB, Moskowitz RW, Jackson BA, Jaffe MW (1963) Studies of illness in the aged. The index of ADL: to standardized measure of biological and psychosocial function. JAMA 185: 914-919

Lawton MP (1998) Scales to measure competence in everyday activities. Psychopharmacol Bull 24: 609-614

Lichtman SM (2004) Chemotherapy in the elderly. Semin Oncol 31: $160-174$

Liu G, Franssen E, Fitch MI, Warner E (1997) Patient preferences for oral vs intravenous palliative chemotherapy. J Clin Oncol 15: 110-115

Macdonald JS (2002) Vive la difference: sex and fluorouracil toxicity. J Clin Oncol 20: $1439-1441$

Mattioli R, Recchia F, Lippe P, Massacesi C, Lalli A, D'Addario M, Imperatori L, Marcucci F, Bonsignori M (2003) Bi-fractionated 'folfox' as first line chemotherapy (CT) in elderly patients with metastatic colorectal cancer. Proc Am Soc Clin Oncol 22: 351 (abstr. 1411)

Miwa M, Ura M, Nishida M, Sawada N, Ishikawa T, Mori K, Shimma N, Umeda I, Ishitsuka H (1998) Design of a novel oral fluoropyrimidine carbamate, capecitabine, which generates 5-fluorouracil selectively in tumours by enzymes concentrated in human liver and cancer tissue. Eur J Cancer 34: 1274-1281

Potosky A, Harlan LC, Kaplan RS, Johnson KA, Lynch CF (2002) Age, sex, and racial differences in the use of standard adjuvant therapy for colorectal cancer. J Clin Oncol 20: $1192-1202$

Prandoni P, Bernardi E (1990) Upper extremity deep vein thrombosis. Curr Opin Pulm Med 5: 222-226

Saltz LB, Cox JV, Blanke C, Rosen LS, Fehrenbacher L, Moore MJ, Maroun JA, Ackland SP, Locker PK, Pirotta N, Elfring GL, Miller LL (2000) Irinotecan plus fluorouracil and leucovorin for metastatic colorectal cancer. N Engl J Med 343: 905-914

Sastre J, Massuti B, Tabernero JM, Chaves M, Reina J, Aparicio J, Queralt B, Maurel J, Díaz-Rubio E, Aranda E (2005) Preliminary results of a randomized phase III trial of the TTD Group comparing capecitabine and oxaliplatin (CapeOx) vs oxaliplatin and 5-fluorouracil in continuous infusion (5-FU CI) as first line treatment in advanced or metastatic colorectal cancer (CRC). Proc Am Soc Clin Oncol 23: 252 (abstr. 3524)

Scheithauer W, McKendrick J, Begbie S, Borner M, Burns WI, Burris HA, Cassidy J, Koralewsky P, Levine EL, Marschner N, Marooun J, García-
Alfonso P, Tujakowsky J, Van Hazel G, Wong A, Zalusky J, Twelves C, X-ACT Study Group (2003) Oral capecitabine as an alternative to i.v. 5-fluorouracil-based adjuvant therapy for colon cancer: safety results of a randomized, phase III trial. Ann Oncol 14: 1735-1743

Schüller J, Cassidy J, Dumont E, Roos B, Durston S, Banken L, Utoh M, Mori K, Weidekamm E, Reigner B (2000) Preferential activation of capecitabine in tumor following oral administration to colorectal cancer patients. Cancer Chemother Pharmacol 45: 291-297

Shields AF, Zalupski MM, Marshall JL, Meropol NJ (2004) Treatment of advanced colorectal carcinoma with oxaliplatin and capecitabine: a phase II trial. Cancer 100: $531-537$

Simmonds PD, Best LY (1999) Should chemotherapy be used as a treatment of advanced colorectal carcinoma (ACC) in patients over 70 years age? Contra. Eur J Cancer 35: 1640 - 1649

Simon R (1989) Optimal two-stage designs for phase II clinical trials. Control Clin Trials 10: $1-10$

Sundarajan V, Grann VR, Neugut AI (1999) Population based variation in the use of chemotherapy for colorectal cancer in the elderly. Proc Am Soc Clin Oncol 18: 413, (abstr. 1598)

Therasse P, Arbuck SG, Eisenhauer EA, Wanders J, Kaplan RS, Rubinstein L, Verweij J, Van Glabbeke M, van Oosterom AT, Christian MC, Gwyther SG (2000) New guidelines to evaluate the response to treatment in solid tumors. European Organization for Research and Treatment of Cancer, National Cancer Institute of the United States, National Cancer Institute of Canada. J Natl Cancer Inst 92: 205-216

Tournigand C, André T, Achille E, Lledo G, Flesh M, Mery-Mignard D, Quinaux E, Couteau C, Buyse M, Ganem G, Landi B, Colin P, Louvet C, de Gramont A (2004) FOLFIRI followed by FOLFOX6 or the reverse sequence in advanced colorectal cancer: a randomized GERCOR study. J Clin Oncol 22: 229-237

Twelves C, Wong A, Nowacki MP, Abt M, Burris III H, Carrato A, Cassidy J, Cervantes A, Fagerberg J, Georgoulias V, Husseini F, Jodrell D, Koralewsky $\mathrm{P}$, Kroning $\mathrm{H}$, Maroun J, Marschner N, McKendrick J, Pawlicky M, Rosso R, Schuller J, Seitz JF, Stabuc B, Tujakowsky J, Van Hazel G, Zaluski J, Scheithauer W (2005) Capecitabine as adjuvant treatment for stage III colon cancer. $N$ Engl J Med 352: $2696-2704$

Van Cutsem E, Twelves C, Cassidy J, Allman D, Bajetta E, Boyer M, Bugat R, Findlay M, Frings S, Jahn M, McKendrick J, Osterwalder B, Pérez-Manga G, Rosso R, Rougier P, Schmiegel WH, Seitz JF, Thompson P, Vieitez JM, Weitzel C, Harper P, Xeloda Colorectal Cancer Study Group (2001) Oral capecitabine compared with intravenous fluorouracil plus leucovorin in patients with metastatic colorectal cancer: results of a large phase III study. J Clin Oncol 19: 4097-4106

Verso M, Agnelli G (2003) Venous thromboembolism associated with longterm use of central venous catheters in cancer patients. J Clin Oncol 21: $3665-3675$

Zeuli M, Nardoni C, Pino MS, Gamucci T, Gabriele A, Ferraresi V, Giannarelli D, Cognetti F (2003) Phase II study of capecitabine and oxaliplatin as first-line treatment in advanced colorectal cancer. Ann Oncol 14: $1378-1382$ 